\title{
The trans-Sialidase from Trypanosoma cruzi a Putative Target for Trypanocidal Agents
}

\author{
Lucia Mendonça-Previato*, Adriane Regina Todeschini, Leonardo Freire de Lima and \\ Jose Osvaldo Previato
}

\author{
Instituto de Biofísica Carlos Chagas Filho, Centro de Ciências da Saúde - Bloco G, Universidade Federal do Rio de \\ Janeiro, 21944-970, Rio de Janeiro-RJ, Brasil
}

\begin{abstract}
Trypanosomatid protozoa are parasites of considerable medical and economical importance because they are the causative agents of chronic human and livestock diseases endemic in developing countries. Trypanosoma cruzi is the causative agent of Chagas' disease, present in most of Latin America. The biology of this parasite presents some unusual features, one of which is the mechanism employed for the addition of sialic acid units to its own glycoproteins, the mucinlike molecules, or to exogenous glycoconjugates. This is mediated by a transglycosylase for sialic acid known as transsialidase and located on the external surface of the parasite, rather than by an intracellular CMP-sialic acid-dependent sialyltransferase. The Trypanosoma cruzi trans-sialidase is thought to play an important role in the pathogenesis of Chagas' disease, and it represents a potential therapeutic target.
\end{abstract}

Keywords: Trypanosoma cruzi, Chagas' disease, trans-sialidase, Mechanism of catalysis.

\section{INTRODUCTION}

Although sialic acid-containing glycoproteins have been described in $T$. cruzi, this parasite is unable to synthesize this monosaccharide from precursors such as acetate or $\mathrm{N}$ acetylmannosamine [1]. The first evidence for the presence of sialic acid in $T$. cruzi was provided by Pereira $e t$ al. [2], who demonstrated that epimastigote forms of parasite can be agglutinated by wheat germ agglutinin (WGA), a lectin that recognizes terminal sialic acids. Subsequent studies described the presence of sialic acid in tripomastigote forms of $T$. cruzi [3]. The question of how T. cruzi acquired a sialic acid-containing surface phenotype led our laboratory to search for an alternative pathway of sialic acid incorporation in this parasite. Previato et al. [4] proposed a novel pathway for the incorporation of sialic acid into $T$. cruzi glycoproteins, involving a transglycosylase for sialic acid, instead of a CMP-sialic acid-dependent sialyltransferase. In that work our group found that epimastigotes grown in the presence of fetal calf serum (FCS) displayed sialoglycoproteins, while those grown in the absence of FCS had only asialoglycoproteins. Treatment of epimastigotes grown in FCS with Clostridium perfringes neuraminidase abolishes WGA binding and instead enhances the binding of PNA, a lectin that recognizes terminal residues of $\beta$-galactose [2]. If the sialidasetreated parasites were incubated with sialyllactose or fetuin, but not with free sialic acid, they regained the ability to bind WGA, with concomitant reduction of PNA binding [4]. Then characterization of the sialic acid isolated from trypomastigotes retrieved from mouse infection showed that this was $\mathrm{N}$-glycolylneuraminic acid [5], the type of sialic acid found

\footnotetext{
*Address correspondence to this author at the Instituto de Biofísica Carlos Chagas Filho, Centro de Ciências da Saúde - Bloco G, Universidade Federal do Rio de Janeiro - 21944 970, Cidade Universitária, Ilha do Fundão, Rio de Janeiro-RJ, Brasil; Tel: +552125626646; Fax: +552122808193; E-mail: luciamp@biof.ufrj.br
}

in mouse serum glycoproteins. The presence of transsialidase activity in trypomastigotes was later proven by Schenkman et al. [6] from the classical biochemical point of view. These and other findings $[7,8]$ led to the current model, in which $T$. cruzi has an obligate adaptation to obtain sialic acid from its hosts, fulfilling this need through transsialidase-mediated transfers from sources in its vicinity; this remains today one of the most interesting aspects of $T$. cruzi glycobiology. The present review deals with the biological aspects of the T. cruzi trans-sialidase relevant to this enzyme as a target, and with the current status of the efforts towards the rational design of drugs that inhibit the $T$. cruzi transsialidase (TcTS).

\section{THE ROLES OF TcTS}

trans-Sialidase is not a single protein. Rather, TS is a collective name that describes the products of a few hundred different genes with considerable sequence divergence among them. These genes encode both for molecules with trans-sialidase enzymatic activity and for proteins with functions unrelated to the transfer of sialic acid, such as the members of the $85 \mathrm{kDa}$ glycoprotein family (Tc-85) [9] which is the subject of a recent review [10].

The ability to trans-sialylate $T$. cruzi surface mucins [11, 12] and host glycoconjugates [5] determines that TS may function in modulating host-parasite interaction, both on the trypomastigote surface or as a soluble mediator. Initial reports indicated that TcTS promoted host cell invasion [6], and precluded the action of lytic antibodies [13]. Alternatively, the enzyme was suggested to sialylate host cell glycomolecules, generating receptors used by the trypanosome for adherence to and penetration of target cells. Results with sialic acid-deficient mutants of Chinese Hamster Ovary cells support this hypothesis, as sialic acid-deficient cells are infected to a lesser degree than wild type cells $[14,15]$. However, recent studies by Rubin-de-Celis et al. [16] suggest that 
a major function of TcTS in host cell infection is to facilitate the escape from the parasitophorous vacuole into the cytosol; sialic acid may act as a barrier against parasite escape from the vacuole, as this escape was faster in sialic-acid-deficient cells.

The biological relevance of soluble TcTS could involve effects on the host immune system. Chenkova and Pereira [17] showed that in vivo injection of minute amounts of purified TcTS increases subsequent parasitemia and mortality in mice infected with $T$. cruzi. Exacerbation of virulence was abrogated by pre-incubation of the enzyme before administration with a monoclonal antibody that inhibits its enzymatic activity. These results have been verified more recently by Risso et al. [18]. However, the molecular mechanisms underlying parasite virulence associated with transsialidase activity have not been elucidated.

TcTS may have a role in immunomodulation of the infected host. Administration of the soluble enzyme to noninfected mice induces certain events that characterize the acute phase of Chagas' disease, such as thrombocytopenia which is brought about by a reduction in the sialic acid content of platelets [19]; $\mathrm{T}$ and $\mathrm{B}$ cell activation [20, 21]; and a marked thymic involution [22]. With respect to T and B-cell activation, it should be mentioned that a non-specific, polyclonal, lymphocyte response constitutes one of the main factors hampering parasite control by the immune system during early infection [23].

Another intriguing and very well documented property of TcTS proteins is their capacity to induce host cell apoptosis $[22,24-26]$. It has been shown that the pro-apoptotic effects of TS on T cells are directly associated with the resialylation of glycomolecules present in double negative thymocytes in the thymic cortex, and in spleen T cells [26]. However, a possibility that should not be ruled out is that thymocite and T-cell apoptosis is brought about by the removal of sialic acid by the TcTS sialidase activity, together with the action of members of the galectin family. $O$ and $N$ linked glycomolecules present in all leukocyte surfaces possess repetitive units of $\mathrm{N}$-acetilglucosamine (GlcNAc) and $\beta 1,4$ linked galactose (Gal). This disaccharide is a minimal ligand for galectin-family members [27]. Furthermore, the repetitive Gal $1,4 \mathrm{GlcNAc}$ units, forming linear structures knowing as polylactosamine chains, can be ligands for the galectins [28], in particular for galectin-1, the pro-apoptotic effects of which are very well documented in a range of cell types [29-33]. The terminal Gal residue of such lactosamine chains can be modified by the action of sialyltransferases [34], resulting in terminally sialylated chains that are no longer galectin ligands. It is therefore possible to speculate that the removal of $\alpha 2,3$-linked sialic acid decorating terminal $\mathrm{Gal}$ residues in lactosamine chains by the sialidase activity in TcTS could generate a significant number of sites for galectin-1 binding, thus contributing to apoptosis.

Recently, our group demonstrated that $T$. cruzi uses its TS enzyme to resialylated the $\mathrm{CD} 8^{+} \mathrm{T}$ cell surface, dampening Ag-specific $\mathrm{CD}^{+} \mathrm{T}$ cell responses thus favouring its own persistence in the mammalian host [35].

Although several works demonstrate that the biological effects induced by TcTS proteins are restricted to the active enzymes, other results showed that the enzymatically inactive TcTS [36] is a sialic acid-binding lectin that co stimulates host $T$ cells through leucosialin (CD43) engagement [37]. In addition, Dias et al. [38] observed that inactive TcTS is able to bind to sialyl residues present in endothelial cells, triggering NF-kappaB activation and subsequent expression of adhesion molecules, thus facilitating parasite entry into host cells.

\section{MECHANISM OF CATALYSIS OF TcTS}

TcTS is a member of the family number 33 of glycoside hydrolases (GH-33) that essentially includes the bacterial and eukaryotic exo-alpha sialidases (http://www.cazy.org) [39]. However, TS preferentially catalyzes the transfer of sialic acid residues from Sia $\alpha 2-3 \mathrm{Gal} \beta 1-x$-containing donors to terminal $\beta$-galactopyranosyl ( $\beta$-Gal $p$ ) containing acceptors, attaching them in $\alpha 2-3$ linkage [40]. Terminal $\alpha$-Gal, Gal $11-4$ (Fuc $\alpha 1-3$ )GlcNAc and Galß1-3(Fuc $\alpha 1-4)$ GlcNAc are not acceptors [41]. Incorporation of one $N$ acetylneuraminic acid (Neu5Ac) residue onto an acceptor appears to hinder the entry of a second residue when two potential acceptor sites are present on the same oligosaccharide [12]. In the absence of a suitable carbohydrate acceptor, TS irreversibly transfers sialic acid to a water molecule, thus functioning as a sialidase similar to viral, mammalian and bacterial sialidases. Although the enzyme differs from those sialidases in acceptor specificity, it shares the same sixbladed $\beta$-propeller fold for the catalytic domain, and has the same key catalytic amino acids found in sialidases from bacteria [42-44], viruses [45-47], trypanosomes [48, 49], leech [50] and humans [51]. The crystal structure obtained a few years ago confirms that the molecular architecture of the TcTS active site preserves several conserved features of microbial sialidases: $a$ ) the arginine triad $\left(\mathrm{Arg}^{35}, \mathrm{Arg}^{245}, \mathrm{Arg}^{314}\right)$ that interacts with the carboxylate group present in the sialic acid derivatives, and $b$ ) the $\mathrm{Glu}^{357}$ residue that stabilizes $\mathrm{Arg}^{35}$, a Tyr ${ }^{342}$, a Glu ${ }^{230}$ and an $\mathrm{Asp}^{59}$ at the reaction center, necessary for the catalytic activity [49]. All sialidases so far studied, as well as TcTS, catalyze sialoside hydrolysis with retention of configuration [52]. However, despite being glycosylases, these enzymes do not possess an aspartate or glutamate residue appropriately positioned to act as a nucleophile in a double-displacement mechanism [53], which suggests an alternative mechanism of hydrolysis. The evidence of production of traces of 2-deoxy-2,3-didehydro- $N$ - acetylneuraminic acid (Neu5Ac2en) after prolonged incubation of $\alpha(2-3)$-sialyllactose [52], together with the TS crystal structure obtained by Buschiazzo et al. [49], pointed towards a transition-state involving oxocarbonium ion intermediate. Such an intermediate was previously proposed for sialoside hydrolysis by viral sialidases [46], which like bacterial sialidases are known to use an SN1 reaction in their mechanisms of catalysis [54].

Concurrent works based on deuterium and carbon isotope effects presented evidence that TS catalyses sialoside hydrolysis through a pathway involving a sialyl-enzyme covalent intermediary [55]. Further, Watts et al. [56], using the $\alpha 2,3$-difluoro- $N$-acetylneuraminic acid to inactivate TcTS have shown by mass spectrometry that the enzyme becomes covalently modified on the active site Tyr residue by the 3fluorosialyl moiety, consistent with the $\mathrm{Tyr}^{342}$ residue being 
the catalytic nucleophile of TS. On the basis of structural [57] and kinetic studies [58], it was proposed that the Asp ${ }^{59}$ acts as a general acid/base catalyst in a double-displacement mechanism. In this mechanism, as the sialic acid unit approaches the enzyme, it displaces the $\mathrm{Tyr}^{119}$ away from the binding site [49], and its carboxylate group interacts with the Arg triad, while its acetamido group interacts with Asp ${ }^{96}$; this induces planarization of the sialic acid moiety around the oxygen ring, with $\mathrm{C} 1, \mathrm{C} 2$ and $\mathrm{C} 3$ assuming a ${ }^{4} \mathrm{H}_{5}$ conformation during the transition state. The $\mathrm{C} 2$ suffers nucleophilic attack by $\mathrm{Tyr}^{342}$, assisted by Glu ${ }^{230}$ acting as a general base, and a covalent linkage is formed. The covalent intermediate assumes a ${ }^{2} C_{5}$ conformation. The aglycone leaves the catalytic cleft, thus making space for binding of the sialic acid acceptor. Transfer to the acceptor would then occur through attack of the $\mathrm{C} 2$ of the sialyl-enzyme intermediate by water or by the 3-OH group of a lactose moiety, which must be deprotonated by the residue acting as acid/base catalyst, $\mathrm{Asp}^{59}$ [58]. This is a classical ping-pong mechanism similar to that of other glycosydases [53].

Nevertheless, this model would allow a water molecule to attack the sialosyl-enzyme intermediate before lactose reaches its binding site, resulting in simple hydrolysis rather than in efficient sugar transfer. A mechanism involving a ternary complex, with the lactose moiety located in the acceptor binding site before the transference of sialic acid, would support higher rates for the transference reaction, as the acceptor substrate would dislodge water molecules from the catalytic pocket. This mechanism would need additional conformational rearrangements in the TcTS, since the crystal structure of the enzyme shows a lactose binding site that is too narrow to accommodate the aglycone moiety of the donor substrate and the acceptor moiety simultaneously [49]. However, one cannot rule out the possibility that such rearrangements may take place in solution, as opposed to the crystallized TS. This hypothesis is given support by several experimental observations. The first are kinetic studies of both parasite-derived [41] and recombinant TS [59], which are consistent with a bisubstrate sequential mechanism. The second type of evidence arises from differences in optimal temperature between the trans-glycosylation and the hydrolysis reaction of TS, suggesting the presence of a binding site for the acceptor molecule [59]. The authors proposed that the stronger temperature dependence observed for the trans-glycosylation reaction as compared with the hydrolysis reaction may be explained by a requirement of close proximity between the acceptor and the donor bound to the catalytic site for the trans-glycosylation to take place. Thus, an increase in the reaction temperature might alter the enzyme conformation in a way that changes the distance between the binding sites, changing the relative rate between transglycosylation and hydrolysis reactions [59]. A third type of evidence comes from studies using NMR spectroscopy and an enzymatically inactive analog of TcTS (iTS) presenting a $\mathrm{Tyr}^{342} \rightarrow$ Hys mutation. These studies demonstrated that iTS has the same specificity for potential sialic acid donors as active TcTS, i.e. it binds $\alpha 2,3$ sialic acid containing molecules [37], but it does not bind $\beta \mathrm{Gal}$-containing acceptors, unless a sialoside is also present. Unless a sialoside is also present, suggesting that iTS interacts with its ligands in a sequential ordered bi-ligand mechanism [60]. These results suggest that the correct binding of sialic acid donor to TS may trigger a conformational change in the enzyme that creates the conditions for the formation of a ternary complex. According to this hypothesis, acceptor binding to the enzyme would displace the water molecules from TcTS catalytic cleft before formation the sialyl-enzyme intermediate takes place, facilitating the selective transfer reaction [57]. Finally, surface plasmon resonance results show that lactose binds to an inactive mutant of TS (Asp ${ }^{59} \rightarrow$ Asn) in the presence of $\alpha 2,3$-sialyllactose [49]. This discussion provides that further structural data are needed to shed light into the reaction mechanism that underlies efficient sugar transfer activity rather than simply hydrolysis by TcTS. Given the importance of TS and sialidases as virulence factors in several infections [61], structural and mechanistic works must be relentless, and must take into account that mutations in key amino acids may produce important modifications in the TcTS mechanism catalysis.

Taking the above comments together, the inhibition of the catalytic activity of TcTS is a potential target for rational drug design against $T$. cruzi, especially in the interaction to and prevent of invasion of the parasite into mammalian host cells. The relevant aspects and recent results on chemical inhibitors of TcTS were recently published [62-64].

\section{ACKNOWLEDGEMENTS}

The study was financially supported by Conselho Nacional de Desenvolvimento e Tecnologia (CNPq) Fundação de Amparo à Pesquisa do Estado do Rio de Janeiro and INCTV-CNPq 573547/2008-4.

\section{REFERENCES}

[1] Schauer R, Reuter G, Mühlpfordt H, Andrade AF, Pereira ME. The occurrence of $N$-acetyl- and $N$-glycoloylneuraminic acid in Trypanosoma cruzi. Hoppe Seyler's Z Physiol Chem 1983; 364: 1053 7.

[2] Pereira MEA, Loures MA, Vilalta F, Andrade AFB. Lectin receptors as markers for Trypanosoma cruzi developmental stages and a study of the interaction of wheat germ agglutinin with sialic acid residues on epimastigote cells. J Exp Med 1980; 152: 1375-82.

[3] Couto AS, Zingales B, Lederkremer RM, Colli W. Trypanosoma cruzi: metabolic labeling of trypomastigote sialoglycolipids. Experientia 1985; 41: 736-38.

[4] Previato JO, Andrade AF, Pessolani MC, Mendonça-Previato L. Incorporation of sialic acid into Trypanosoma cruzi macromolecules. A proposal for a new metabolic route. Mol Biochem Parasitol 1985; 16: 85-96.

[5] Previato JO, Andrade AFB, Vermelho A, Firmino JC, MendonçaPreviato L. Evidence for $N$-glycolylneuraminic acid incorporation by Trypanosoma cruzi from infected animals. Mem Inst Oswaldo Cruz 1990; 85: 38-9.

[6] Schenkman S, Jiang MS, Hart GW, Nussenzweig V. A novel cell surface trans-sialidase of Trypanosoma cruzi generates a stagespecific epitope required for invasion of mammalian cells. Cell 1991; 65: 1117-25.

[7] Frasch AC. Functional diversity in the trans-sialidase and mucin families in Trypanosome cruzi. Parasitol Today 2000; 16: 282-6.

[8] Buscaglia CA, Campo VA, Frasch AC, Di Noia JM. Trypanosoma cruzi surface mucins: host-dependent coat diversity. Nat Rev Microbiol 2006; 4: 229-36.

[9] Colli W. trans-Sialidase: a unique enzyme activity discovered in the protozoan Trypanosoma cruzi. FASEB J 1993; 7: 1257-64.

[10] Alves MJ, Colli W. Role of the gp85/trans-sialidase superfamily of glycoproteins in the interaction of Trypanosoma cruzi with host structures. Subcell Biochem 2008; 47: 58-69.

[11] Previato JO, Jones C, Gonçalves LP, Wait R, Travassos LR, Mendonça-Previato L. $O$-glycosidically linked $N$-acetylglucosamine- 
bound oligosaccharides from glycoproteins of Trypanosoma cruzi. Biochem J 1994; 301: 151-9.

[12] Previato JO, Jones C, Xavier MT, et al. Structural characterization of the major glycosylphosphatidylinositol membrane-anchored glycoprotein from epimastigote forms of Trypanosoma cruzi Ystrain. J Biol Chem 1995; 270: 7241-50.

[13] Pereira-Chioccola VL, Acosta-Serrano A, Correia de Almeida I, et $a l$. Mucin-like molecules form a negatively charged coat that protects Trypanosoma cruzi trypomastigotes from killing by human anti-alpha-galactosyl antibodies. J Cell Sci 2000; 113: 1299-307.

[14] Monteiro VG, Soares CP, de Souza W. Host cell surface sialic acid residues are involved on the process of penetration of Toxoplasma gondii into mammalian cells. FEMS Microbiol Lett 1998; 15: 3237.

[15] Ciavaglia MC, de Carvalho TU, de Souza W. Interaction of Trypanosoma cruzi with cells with altered glycosylation patterns. Biochem Biophys Res Commun 1993; 15: 718-21.

[16] Rubin-de-Celis SS, Uemura H, Yoshida N. Schenkman S. Expression of trypomastigote trans-sialidase in metacyclic forms of Trypanosoma cruzi increases parasite escape from its parasitophorous vacuole. Cell Microbiol 2006; 8: 1888-98.

[17] Chuenkova M, Pereira ME. Trypanosoma cruzi trans-sialidase: enhancement of virulence in a murine model of Chagas' disease. $\mathbf{J}$ Exp Med 1995; 1: 1693-703.

[18] Risso MG, Pitcovsky TA, Caccuri RL, Campetella O, Leguizamón MS. Immune system pathogenesis is prevented by the neutralization of the systemic trans-sialidase from Trypanosoma cruzi during severe infections. Parasitology 2007; 134: 503-10.

[19] Tribulatti MV, Mucci J, Van Rooijen N, Leguizamón MS, Campetella $\mathrm{O}$. The trans-sialidase from Trypanosoma cruzi induces thrombocytopenia during acute Chagas' disease by reducing the platelet sialic acid contents. Infect Immunol 2005; 73: 201-07.

[20] Todeschini AR, Nunes MP, Pires RS, et al. Costimulation of host T lymphocytes by a trypanosomal trans-sialidase: involvement of CD43 signaling. J Immunol 2002; 168: 5192-8.

[21] Gao W, Wortis HH, Pereira MA. The Trypanosoma cruzi transsialidase is a T cell-independent B cell mitogen and an inducer of non-specific Ig secretion. Int Immunol 2002; 14: 299-308.

[22] Leguizamón MS, Mocetti E, García Rivello H, Argibay P, Campetella O. trans-Sialidase from Trypanosoma cruzi induces apoptosis in cells from the immune system in vivo. J Infect Dis 1999; 180: 1398-402.

[23] DosReis GA, Freire-de-Lima CG, Nunes MP, Lopes MF. The importance of aberrant $\mathrm{T}$-cell responses in Chagas disease. Trends Parasitol 2005; 21: 237-43.

[24] Mucci J, Hidalgo A, Mocetti E, Argibay PF, Leguizamon MS, Campetella O. Thymocyte depletion in Trypanosoma cruzi infection is mediated by trans-sialidase-induced apoptosis on nurse cells complex. Proc Natl Acad Sci USA 2002; 99: 3896-901.

[25] Mucci J, Mocetti E, Leguizamón MS, Campetella O. A sexual dimorphism in intrathymic sialylation survey is revealed by the trans-sialidase from Trypanosoma cruzi. J Immunol 2005; 15: 4545-50.

[26] Mucci J, Risso MG, Leguizamón MS, Frasch AC, Campetella O. The trans-sialidase from Trypanosoma cruzi triggers apoptosis by target cell sialylation. Cell Microbiol 2006; 8: 1086-95.

[27] Merkle RK, Cummings RD. Asparagine-linked oligosaccharides containing poly- $\mathrm{N}$-acetyllactosamine chains are preferentially bound by immobilized calf heart agglutinin. J Biol Chem 1998; 5: 16143-9.

[28] Zhou Q, Cummings RD. L-14 lectin recognition of laminin and its promotion of in vitro cell adhesion. Arch Biochem Biophys 1993; 300: 6-17.

[29] Perillo NL, Pace KE, Seilhamer JJ, Baum LG. Apoptosis of T cells mediated by galectin-1. Nature 1995; 14: 736-9.

[30] Pace KE, Hahn HP, Pang M, Nguyen, JT, Baum LG. CD7 delivers a pro-apoptotic signal during galectin-1-induced $\mathrm{T}$ cell death. $\mathrm{J}$ Immunol 2000; 1: 2331-44.

[31] Hernandez JD, Nguyen JT, He J, et al. Galectin-1 binds different CD43 glycoforms to cluster CD43 and regulate T cell death. J Immunol 2006; 15: 5328-36

[32] Toscano MA, Bianco GA, Ilarregui JM, et al. Differential glycosylation of TH1, TH2 and TH-17 effector cells selectively regulates susceptibility to cell death. Nat Immunol 2007; 8: 825-34.

[33] Koh HS, Lee C, Lee KS, et al. CD7 expression and galectin-1induced apoptosis of immature thymocytes are directly regulated by NF-kappaB upon T-cell activation. Biochem Biophys Res Commun 2008; 23: 149-53.

[34] Harduin-Lepers A, Vallejo-Ruiz V, Krzewinski-Recchi MA, Samyn-Petit B, Julien S, Delannoy P. The human sialyltransferase family. Biochimie 2001; 83: 727-37.

[35] Freire-de-Lima L, Allison-Silva F, Carvalho ST et al. Trypanosoma cruzi subverts host cell sialylation and may compromise antigen-specific $\mathrm{CD}^{+} \mathrm{T}$ cell responses. J Biol Chem 2010; 285: 13388-96.

[36] Cremona ML, Sánchez DO, Frasch AC, Campetella O. A single tyrosine differentiates active and inactive Trypanosoma cruzi transsialidases. Gene 1995; 160: 123-8.

[37] Todeschini AR, Girard MF, Wieruszeski JM, et al. trans-Sialidase from Trypanosoma cruzi binds host T-lymphocytes in a lectin manner. J Biol Chem 2002; 277: 45962-8.

[38] Dias WB, Fajardo FD, Graça-Souza AV, et al. Endothelial cell signalling induced by trans-sialidase from Trypanosoma cruzi. Cell Microbiol 2008; 10: 88-99.

[39] Achyuthan KE, Achyuthan AM. Comparative enzymology, biochemistry and pathophysiology of human exo-alpha-sialidase (neuraminidases). Comp Biochem Physiol B Biochem Mol Biol 2001; 129: 29-64.

[40] Vandekerckhove F, Schenkman S, Pontes de Carvalho L, et al. Substrate specificity of the Trypanosoma cruzi trans-sialidase. Glycobiology 1992; 2: 541-8.

[41] Scudder P, Doom JP, Chuenkova M, Manger ID, Pereira ME Enzymatic characterization of beta-D-galactoside alpha 2,3-transsialidase from Trypanosoma cruzi. J Biol Chem 1993; 268: 988691.

[42] Crennell SJ, Garman EF, Laver WG, Vimr ER, Taylor GL. Crystal structure of a bacterial sialidase (from Salmonella typhimurium LT2) shows the same fold as an influenza virus neuraminidase. Proc Natl Acad Sci USA 1993; 90: 9852-6.

[43] Crennell SJ, Garman E, Laver G, Vimr ER, Taylor G. Crystal structure of Vibrio cholerae neuraminidase reveals dual lectin-like domains in addition to the catalytic domain. Structure 1994; 2 : 535 44.

[44] Gaskell A, Crennell SJ, Taylor G. The three domains of a bacterial sialidase: a beta-propeller, an immunoglobulin module and a galactose-binding jelly-roll. Structure 1995; 3: 1197-205.

[45] Varghese JN, Laver WG, Colman PM. Structure of the influenza virus glycoprotein antigen neuraminidase at $2.9 \mathrm{~A}$ resolution. $\mathrm{Na}-$ ture 1983; 303: 35-40

[46] Burmeister WP, Henrissat B, Bosso C, Cusack C, Ruigrok RWH Influenza $\mathrm{B}$ virus neuraminidase can synthesize its own inhibitor Structure 1993; 1: 19-26.

[47] Crennell SJ, Takimoto T, Portner A, Taylor G. Crystal structure of the multifunctional paramyxovirus hemagglutinin-neuraminidase. Nat Struct Biol 2000; 7: 1068-74.

[48] Buschiazzo A, Tavares GA, Campetella O, et al. Structural basis of sialyltransferase activity in trypanosomal sialidases. EMBO J 2000; 19: 16-24.

[49] Buschiazzo A, Amaya MF, Cremona ML, Frasch AC, Alzari PM. The crystal structure and mode of action of trans-sialidase, a key enzyme in Trypanosoma cruzi pathogenesis. Mol Cell 2002; 10: 758-68.

[50] Lou Y, Li SC, Chou MY, Li YT, Lou M. The crystal structure of an intramolecular trans-sialidase with a NeuAc alpha2,3Gal specificity. Structure 1998; 6: 521-30.

[51] Chavas LM, Tringali C, Fusi P, et al. Crystal structure of the human cytosolic sialidase Neu2. Evidence for the dynamic nature of substrate recognition. J Biol Chem 2005; 280: 469-75.

[52] Todeschini AR, Mendonça-Previato L, Previato JO, Varki A, van Halbeek H. trans-Sialidase from Trypanosoma cruzi catalyzes sialoside hydrolysis with retention of configuration. Glycobiology 2000; 10: 213-21.

[53] Davies GJ, Gloster TM, Henrissat B. Recent structural insights into the expanding world of carbohydrate-active enzymes. Curr Opin Struct Biol 2005; 15: 637-45.

[54] Vasella A, Davies GJ, Böhm M. Glycosidase mechanisms. Curr Opin Chem Biol 2002; 6: 619-29.

[55] Yang J, Schenkman S, Horenstein BA. Primary 13C and betasecondary $2 \mathrm{H}$ KIEs for trans-sialidase. A snapshot of nucleophilic participation during catalysis. Biochemistry 2000; 39: 5902-10.

[56] Watts AG, Damager I, Amaya ML, et al. Trypanosoma cruzi transsialidase operates through a covalent sialyl-enzyme intermediate: 
tyrosine is the catalytic nucleophile. J Am Chem Soc 2003; 25; 125: 7532-3.

[57] Amaya MF, Watts AG, Damager I, et al. Structural insights into the catalytic mechanism of Trypanosoma cruzi trans-sialidase. Structure 2004; 12: 775-84

[58] Damager I, Buchini S, Amaya MF, et al. Kinetic and mechanistic analysis of Trypanosoma cruzi trans-sialidase reveals a classical ping-pong mechanism with acid/base catalysis. Biochemistry 2008; 47: 3507-12.

[59] Ribeirão M, Pereira-Chioccola VL, Eichinger D, Rodrigues MM, Schenkman S. Temperature differences for trans-glycosylation and hydrolysis reaction reveal an acceptor binding site in the catalytic mechanism of Trypanosoma cruzi trans-sialidase. Glycobiology 1997; 7: 1237-46.

[60] Todeschini AR, Dias WB, Girard MF, Wieruszeski JM, MendonçaPreviato L, Previato JO. Enzymatically inactive trans-sialidase from Trypanosoma cruzi binds sialyl and beta-galactopyranosyl residues in a sequential ordered mechanism. J Biol Chem 2004; 279: 5323-8.

[61] Schauer R. Sialic acids as regulators of molecular and cellular interactions. Curr Opin Struct Biol 2009; 19: 507-14.

[62] Neres J, Bryce RA, Douglas KT. Rational drug design in parasitology: trans-sialidase as a case study for Chagas disease. Drug Discov Today 2008; 13: 110-17.

[63] Neres J, Brewer ML, Ratier L, et al. Discovery of novel inhibitors of Trypanosoma cruzi trans-sialidase from in silico screening. Bioorg Med Chem Lett 2009; 19: 589-96.

[64] Carvalho ST, Sola-Penna M, Oliveira IA, et al. A new class of mechanism-based inhibitors for Trypanosoma cruzi trans-sialidase and their influence on parasite virulence. Glycobiology 2010; 20: $1034-45$

(C) Mendonça-Previato et al.; Licensee Bentham Open.

This is an open access article licensed under the terms of the Creative Commons Attribution Non-Commercial License (http://creativecommons.org/licenses/by-nc/3.0/) which permits unrestricted, non-commercial use, distribution and reproduction in any medium, provided the work is properly cited. 